\title{
Chemopreventive Effect of Metformin on Gastric Cancer Development
}

\author{
Ka Shing Cheung ${ }^{1,2}$, Kit Lam Chung ${ }^{3}$, and Wai K. Leung ${ }^{1}$ \\ ${ }^{1}$ Department of Medicine, The University of Hong Kong, Queen Mary Hospital, Hong Kong, ${ }^{2}$ Department of Medicine, The University of \\ Hong Kong-Shenzhen Hospital, Shenzhen, and ${ }^{3}$ Li Ka Shing Faculty of Medicine, The University of Hong Kong, Hong Kong, China
}

\section{Article Info}

Received March 25, 2021

Revised April 17, 2021

Accepted May 12, 2021

Published online June 25, 2021

Corresponding Author

Wai K. Leung

ORCID https://orcid.org/0000-0002-5993-1059

E-mail waikleung@hku.hk

\begin{abstract}
Although Helicobacter pylori infection is the most important causative factor for gastric cancer (GC), $H$. pylori eradication alone does not completely eliminate the GC risk. In addition to $H$. pylori eradication, other risk factors for GC should be identified and targeted. Diabetes mellitus (DM) confers a $20 \%$ increased risk of GC, which could be mediated via several biological mechanisms including the stimulation of cell proliferation via hyperinsulinemia and increased insulingrowth factor production, the promotion of angiogenesis, and DNA damage. With a current global prevalence of $9.3 \%$ and a predicted rise to $10.2 \%$ by 2030 , DM could contribute substantially to the burden of GC cases worldwide. Emerging evidence showed that metformin possesses chemopreventive effects via both direct (e.g., adenosine monophosphate-activated protein kinase activation and subsequent inhibition of the mammalian target of rapamycin pathway) and indirect (e.g., modulation of the interaction between tumor cells and their microenvironment and gut microbiota) pathways. A recent meta-analysis of observational studies showed that metformin use was associated with $24 \%$ lower GC risk. However, many available observational studies related to metformin effects suffered from biases including the failure to adjust for the $H$. pylori infection status and serial glycemic control and time-related biases. Future prospective studies addressing these pitfalls are needed. (Gut Liver 2022;16:147-156)
\end{abstract}

Key Words: Helicobacter pylori; Chemoprevention; Diabetes mellitus; Metformin; Gut microbiota

\section{INTRODUCTION}

Gastric cancer (GC) is the fifth most common cancer worldwide, with more than one million new cases $(5.7 \%$ of all incident cancer cases) in 2018. ${ }^{1}$ The incidence has great regional variability, being the highest in East Asia (in particular China, Japan, and Korea) where around half of the new cases are diagnosed, followed by Latin America and Eastern Europe. The overall 5-year survival rate is only $25 \%$ to $30 \%$ as around two-thirds of patients are diagnosed at an advanced stage in which curative surgery is not possible. ${ }^{3,4}$ Despite the advances in chemotherapy, the prognosis remains dismal in patients with advanced disease, with a median survival of less than 1 year.

The most important causative factor for GC development is Helicobacter pylori infection with a relative risk of 2.8 as shown in a recent meta-analysis. ${ }^{5} \mathrm{H}$. pylori has been classified as class I human carcinogen by the International Agency for Research on Cancer of the World Health Organization. ${ }^{6}$ With a global prevalence of $H$. pylori ranging from $19 \%$ to $88 \%$ in adults, ${ }^{7}$ it is estimated that $H$. pylori infection attributes to $89 \%$ of non-cardia GC cases, which in turn accounts for $78 \%$ of all GC cases. ${ }^{8}$ It is postulated that $H$. pylori infection triggers and promotes the Correa's gastric carcinogenesis cascade ${ }^{9}$-a sequential change of the gastric mucosa from chronic gastritis to atrophic gastritis, intestinal metaplasia, dysplasia, and finally adenocarcinoma. In a population-based cohort study, the risk of GC was increased in patients with atrophic gastritis, intestinal metaplasia and dysplasia as compared to those with normal gastric mucosa by a hazard ratio (HR) of 4.5, 6.2 and 10.9 , respectively. ${ }^{10}$ Recently, intestinal metaplasia has been recognized as a surrogate biomarker of the genetic instability that promotes the progression of gastric stem cells to 
cancer stem cells.

Although $H$. pylori is the most important cause of GC, eradication of $H$. pylori alone is not enough to eliminate the risk of subsequent GC development. A recent metaanalysis of seven randomized controlled trials (RCTs) of 8,323 subjects (six of which were conducted in East Asian countries), showed that $H$. pylori eradication reduced GC risk by only $46 \% .{ }^{11}$ The fact that a significant proportion of $H$. pylori-eradicated subjects progress to GC is likely related to the presence of baseline pre-cancerous lesions undermining the efficacy of $H$. pylori eradication in reducing GC risk. ${ }^{2,13}$ While $H$. pylori eradication reverses chronic gastritis and atrophic gastritis, prior studies showed that it may not regress intestinal metaplasia lesions, ${ }^{14-16}$ the presence of which was once considered a "point of no return" in the GC cascade. ${ }^{12}$ Moreover, a recent prospective study with a follow-up duration of up to 10 years found no significant difference in the prevalence of intestinal metaplasia between $H$. pylori-eradicated and -infected subjects in their antrum and corpus, after the follow-up periods of $\geq 5$ and $\geq 3$ years, respectively. ${ }^{17}$ In contrast, a study that observed 2,258 patients for up to 15 years showed that $H$. pylori eradication reduced GC risk even in those with intestinal metaplasia and dysplasia. ${ }^{18}$ The above-mentioned meta-analysis also included three RCTs of 1,841 patients with confirmed gastric neoplasia who had undergone endoscopic resection, and showed that $H$. pylori eradication could still reduce the subsequent GC risk by about $51 \%$. ${ }^{11}$ Taken together, current evidence suggests that although eradication of $H$. pylori can reduce the GC risk and may regress precancerous gastric mucosal changes, the risk of GC remains in a considerable proportion of subjects even after $H$. pylori eradication. ${ }^{11}$

\section{DIABETES MELLITUS AS RISK FACTOR FOR GC}

Apart from $H$. pylori infection, lifestyle factors could also potentially modulate the risk of precancerous lesions and GC including smoking, alcohol consumption, high salt intake, ingestion of nitrogen-containing compounds, vitamins and antioxidants. ${ }^{19}$ Family history of GC, genetic polymorphism and hereditary cancer syndrome are also contributing factors. Importantly, diabetes mellitus (DM) is a recognized risk factor of GC. ${ }^{20}$

With a global prevalence of $9.3 \%$ in 2019 and a projected rise to $10.2 \%$ by $2030,{ }^{21}$ the potential burden of GC attributable to DM could be substantial. Multiple biological mechanisms associating DM with GC have been proposed, which include the stimulation of cell proliferation via hyperinsulinemia and increased insulin-growth factor (IGF) production, ${ }^{22}$ the promotion of angiogenesis by increasing vascular endothelial growth factor level, ${ }^{23}$ DNA damage by the direct effect of hyperglycemia ${ }^{24}$ and an indirect effect through an increased production of reactive oxygen species. ${ }^{25}$ The carcinogenic effect of DM may also be partly mediated via excessive body weight (overweight and obesity), which is a commonly associated condition. A meta-analysis showed that excess body weight (body mass index $\geq 25 \mathrm{~kg} / \mathrm{m}^{2}$ ) was associated with a 1.2 -fold increase in GC risk, with stratified analysis showing an increased risk for cardia GC (odds ratio [OR], 1.55) but not noncardia GC. ${ }^{26}$ One possible mechanism is the increased risk of gastroesophageal reflux disease (GERD) among subjects with excess body weight, which is a known risk factor for adenocarcinomas of the gastroesophageal junction. ${ }^{27}$ Other proposed mechanisms of how excess body weight increases GC risk include insulin resistance with elevated levels of IGFs, alterations in the levels of adiponectin, leptin, sex steroids and glucocorticoids, obesity-related inflammatory markers, oxidative stresses, and nuclear factor $-\kappa \mathrm{B}(\mathrm{NF}-\kappa \mathrm{B})$ system, resulting in perturbance in the normal balance between cell proliferation, differentiation, and apoptosis. ${ }^{26,28}$

A population-based cohort study of 2,603 Japanese subjects showed the GC risk was higher with higher hemoglobin A1c (HbA1c) levels. ${ }^{29}$ The age- and sex-adjusted incidence of GC among individuals with HbAlc levels of $5.0 \%$ to $5.9 \%, 6.0 \%$ to $6.9 \%$, and $\geq 7.0 \%$ were $2.5,5.1$, and 5.5 per 1,000 person-years. $H$. pylori infection and a higher HbA1c level ( $\geq 6.0 \%)$ had a synergistic effect on GC risk.

There are six meta-analyses investigating the effect of DM on GC risk in the past decade (Table 1). A meta-analysis of 17 observational studies in 2013 showed that DM is associated with a $19 \%$ higher GC risk. ${ }^{20}$ However, there are few studies reporting the effect of DM on GC according to cancer subsite. Li et al. ${ }^{18}$ found that there was a significant association between self-reported DM and cardia cancer risk (HR, 1.89; 95\% confidence interval [CI], 1.43 to 2.50 ), while Kim et al. ${ }^{30}$ refuted this association (HR, 0.64; 95\% $\mathrm{CI}, 0.14$ to 2.94 ). However, the individual results included in the meta-analysis showed conflicting results. A subsequent meta-analysis of 15 cohort studies in 2017 refuted the association (pooled risk ratio [pooled RR], 1.10; 95\% CI, 0.94 to 1.29$).^{31}$ This inconsistency could be due to a failure to adjust for $H$. pylori infection status and concomitant medication usage (including proton pump inhibitors [PPIs], aspirin, non-aspirin nonsteroidal anti-inflammatory drugs [NA-NSAIDs], cyclooxygenase [COX)]-2 inhibitors, statins and metformin), which may modulate the risk of GC (to be explained in more detail in next section). The latter potentially biases a positive association between DM 
Table 1. Summary of Meta-Analyses on the Association between Diabetes Mellitus and Gastric Cancer

\begin{tabular}{|c|c|c|c|c|}
\hline Author (year) & Literature search & Study design & No. of included studies & Pooled risk ratio $(95 \% \mathrm{CI})$ \\
\hline Sona et al. $(2018)^{39}$ & Inception till April 2017 & Cohort studies (type I diabetes mellitus) & 9 & $1.44(1.29-1.61)$ \\
\hline \multirow[t]{3}{*}{ Miao et al. $(2017)^{31}$} & Details not available & Cohort studies & 15 & $1.10(0.94-1.29)$ \\
\hline & & Eastern countries & 5 & $0.97(0.72-1.32)$ \\
\hline & & Western countries & 10 & $0.92(0.75-1.14)$ \\
\hline \multirow[t]{3}{*}{ Yoon et al. $(2013)^{20}$} & Inception till February 7, 2012 & $\begin{array}{l}5 \text { Case control studies }+11 \text { cohort studies } \\
+1 \text { nested case control study }\end{array}$ & 17 & $1.19(1.08-1.31)$ \\
\hline & & Eastern countries & 7 & $1.19(1.02-1.38)$ \\
\hline & & Western countries & 10 & $1.18(1.03-1.36)$ \\
\hline \multirow[t]{3}{*}{ Shimoyama $(2013)^{38}$} & 1950 to January 2013 & 2 Case control studies +9 cohort studies & 11 & $1.41(1.10-1.81)$ \\
\hline & & Eastern countries & 5 & $1.77(1.38-2.26)$ \\
\hline & & Western countries & 6 & $1.23(0.90-1.68)$ \\
\hline Tian et al. $(2012)^{40}$ & Inception till October 10, 2011 & 7 Case control studies +18 cohort studies & 25 & $1.11(1.00-1.24)$ \\
\hline \multirow[t]{4}{*}{ Ge et al. $(2011)^{41}$} & Inception till May 31, 2011 & 4 Case control studies +17 cohort studies & 21 & $1.09(0.98-1.22)$ \\
\hline & & Asia & 6 & $1.30(0.95-1.80)$ \\
\hline & & Europe & 8 & $1.00(0.79-1.26)$ \\
\hline & & North America & 7 & $0.96(0.90-1.02)$ \\
\hline
\end{tabular}

$\mathrm{Cl}$, confidence interval.

and GC to null, as a higher proportion of patients with DM may require treatment with aspirin, statins, and metformin, which could potentially harbor chemopreventive effects against GC development. One study also found that the association between DM and subsequent GC risk varied over time, with increasing risk of GC being observed only more than 4 years after diagnosis of DM. ${ }^{32}$

Our recent territory-wide cohort study of 46,460 subjects showed that type II DM was associated with an increased GC risk (adjusted HR [aHR], 1.73; 95\% CI, 1.08 to 2.79 ) even after $H$. pylori eradication, particularly in those with $\mathrm{HbAlc} \geq 6.0 \%$. This association was only found in cardia GC (HR, 3.4; 95\% CI, 1.45 to 7.97$)$, but not in non-cardia GC (HR, 1.53; 95\% CI, 0.84 to 2.78$){ }^{33}$ This differential effect of DM on cancer subsite may be attributed to the association between obesity and GERD and hence cardia cancer. Eradicating $H$. pylori restores gastric acid production by improving corpus inflammation, which may worsen GERD. ${ }^{34}$

It should also be noted that among those meta-analyses which showed a significant association between GC and DM, subgroup analysis showed the harmful effect of DM was limited to Asians but not non-Asians (Table 1). While this geographical difference may be due to higher prevalence of GC risk among Asian countries, the intricate interplay between $H$. pylori infection (with a higher prevalence in the Asians) and metabolic syndrome including DM on GC development may also play a role. ${ }^{35-37}$ Another major limitation of current studies is the failure to distinguish between type I and type II DM, which differ significantly in terms of their metabolic characteristics. ${ }^{38}$ Nevertheless, as type I DM is less frequent than type II DM, majority of patients included in the meta-analyses can be reasonably regarded as having type II DM. Remarkably, there is one meta-analysis including nine studies of type I DM patients only showing a pooled RR of $1.44 .^{39}$ This harmful effect appears to be more prominent compared with other metaanalyses without differentiation of the types of DM. Further studies are warranted to investigate a potential differential effect of the two types of DM on GC development.

\section{PHARMACOLOGICAL AGENTS IN THE MODIFICATION OF GC RISK}

Increasing evidence has emerged to show that certain medications may modulate GC risk. However, majority of these studies included a heterogeneous population of $H$. pylori-infected and $H$. pylori-negative subjects. PPIs lead to profound acid suppression, which could worsen atrophic gastritis, ${ }^{42}$ particularly in $H$. pylori-infected subjects. ${ }^{43,44}$ The increase in gastrin (a potent growth factor that have trophic effect on the gastric mucosa) in response to this resultant hypochlorhydria stimulates enterochromaffin-like cell hyperplasia. ${ }^{43}$ A meta-analysis of seven studies showed that PPIs were associated with a 2.5-fold higher GC risk. ${ }^{45}$ This risk was noted even after $H$. pylori eradication. ${ }^{46}$ However, although an association has been shown, the causality between PPIs and GC development warrants further investigation as current evidence is still conflicting. In a nested case-control study with 1,233 GC cases, ${ }^{47} \mathrm{PPI}$ use of $\geq 2$ years was not associated with higher risk of GC and consistent association was not found for increasing PPI dose. However, in exploratory analyses, PPI use of $\geq 10$ years was associated with a $30 \%$ higher GC risk. In a $3 \times 2$ partial factorial double-blinded RCT involving 
17,598 subjects with cardiovascular disease and peripheral artery disease (and hence were given combination of aspirin and rivaroxaban, aspirin alone or rivaroxaban), participants were randomly assigned to receive pantoprazole 40 mg daily or placebo. ${ }^{48}$ There was no statistically significant difference in multiple safety events except for an increased enteric infection among pantoprazole users. However, this study only reported all gastrointestinal cancers $(n=169)$ without specifying the number of GC cases. It will not be surprising that this study was indeed much underpowered to study the outcome of GC as evidenced by the few cases of gastric atrophy $(n=45)$. Moreover, the median duration of follow-up was only 3 years, which was relatively short to study GC outcomes. Another issue is that a significant proportion of the study participants had concomitant use of aspirin, which is a potential chemopreventive agent against GC. ${ }^{49}$ In fact, post hoc analysis of the territory-wide cohort study showed that PPI-associated GC risk could be offset by concomitant use of aspirin. ${ }^{50}$

Aspirin and statins are relatively inexpensive medications for the treatment and prevention of cardiovascular events. They are also found to possess potential chemopre- ventive effects against solid organ tumors. ${ }^{49}$ Statins exert this effect via halting cell-cycle progression, ${ }^{51}$ inducing apoptosis, ${ }^{52}$ inhibiting angiogenesis, ${ }^{53}$ and inhibiting the growth of tumor cells. ${ }^{54}$ Aspirin inhibits COX-2 and nonCOX pathways, ${ }^{55,56}$ such as phosphatidylinositol 3-kinase, $\mathrm{NF}-\kappa \mathrm{B},{ }^{57}$ Wnt- $\beta$-catenin, extracellular signal-regulated kinase, and activated protein $1 .^{58}$ Meta-analyses of clinical studies reported that the uses of aspirin ${ }^{49}$ and statins ${ }^{59}$ were associated with $36 \%$ and $32 \%$ lower risks of GC respectively. The beneficial effects of both agents are also observed after H. pylori eradication. ${ }^{60,61}$

COX-2 overexpression is detected in gastric intestinal metaplasia and cancer. ${ }^{62}$ Two RCTs have been conducted to investigate the effect of COX-2 inhibitors on intestinal metaplasia. ${ }^{63,64}$ One study showed that rofecoxib use for 2 years did not regress intestinal metaplasia or its severity in $H$. pylori-eradicated subjects with intestinal metaplasia. ${ }^{63}$ Another study showed that celecoxib use for 2 years regressed advanced gastric lesions in $H$. pylori-infected but not $H$. pylori-eradicated subjects. ${ }^{64}$ As for NA-NSAIDs, our recent territory-wide cohort study of 92,017 H. pylorieradicated subjects found that NA-NSAID use was not

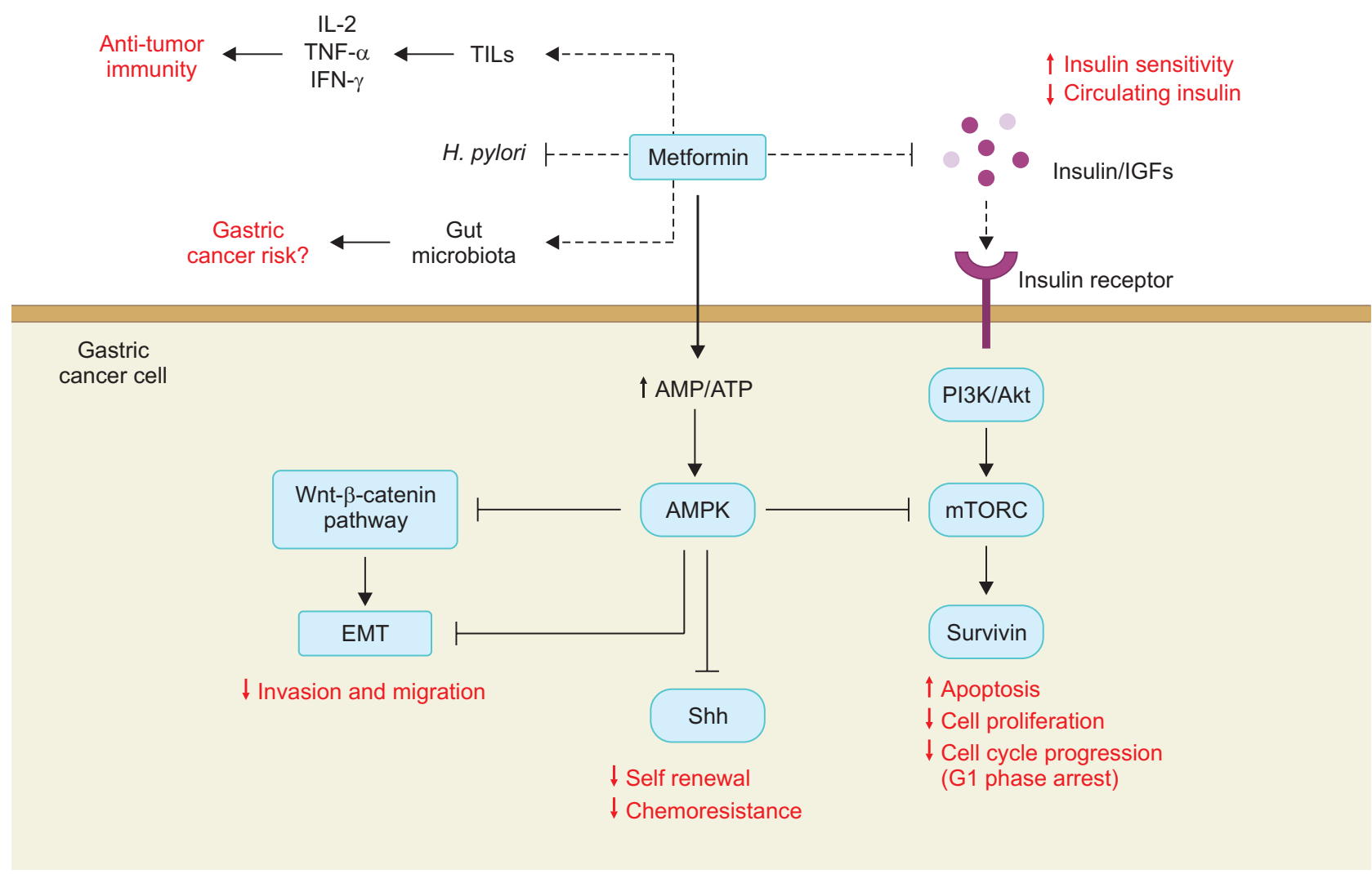

Fig. 1. Mechanisms underlying the chemopreventive effects of metformin.

IL-2, interleukin-2; TNF- $\alpha$, tumor necrosis factor $\alpha$; IFN- $\gamma$, interferon $\gamma$; TILs, tumor-infiltrating lymphocytes; H. pylori, Helicobacter pylori; IGFs, insulin-growth factors; AMP, adenosine monophosphate; ATP, adenosine triphosphate; AMPK, AMP-activated protein kinase; EMT, epithelial-tomesenchymal transition; Shh, sonic hedgehog; PI3K, phosphoinositide 3-kinase; Akt, protein kinase B; mTORC, mammalian target of rapamycin complex. Solid lines and dotted lines represent direct and indirect effects of metformin on gastric cancer development. 
associated with a lower risk for GC. ${ }^{65}$ An updated metaanalysis in this study showed that the pooled adjusted RR was 0.88 (95\% CI, 0.77 to 1.01 ).

\section{METFORMIN IN REDUCING GC} DEVELOPMENT

\section{Anti-tumorigenic mechanisms of metformin on GC development}

The anti-cancer activity by metformin is proposed to be mediated by several pathways (Fig. 1). First, as metfor$\mathrm{min}$ is an insulin sensitizer, it reduces the production of insulin and IGFs. This cripples the IGF signaling pathway that facilitates the proliferation of cancer cells expressing IGF receptors. ${ }^{22}$ Secondly, the activation of adenosine monophosphate-activated protein kinase (AMPK) and the subsequent inhibition of the mammalian target of rapamycin complex 1 pathway and survivin (one of the inhibitor of apoptosis proteins family that is associated with poor prognosis in GC $)^{66,67}$ is shown to induce cancer cell apoptosis. ${ }^{68,69}$ Other potential direct anti-carcinogenic mechanisms of metformin include anti-proliferative effect on gastric cell lines causing G1 cell-cycle arrest, ${ }^{70,71}$ the inhibition of the Wnt- $\beta$-catenin pathway, ${ }^{72}$ a reversal of epithelial-to-mesenchymal transition, ${ }^{73-75}$ AMPK-dependent inhibition of the sonic hedgehog signaling pathway, ${ }^{76}$ which is essential for the maintenance of self-renewal and chemoresistance of cancer stem cells, and targeting cancer stem cells and progenitor cells. ${ }^{77}$ It is noteworthy that these anti-tumorigenic effects of metformin are also applicable to other solid organ cancers. ${ }^{78}$ A number of meta-analyses of cohort and case-control studies have revealed a $10 \%$ to $40 \%$ lower overall cancer risk. ${ }^{78}$ In a meta-analysis of 41 observational studies of more than one million patients with type $2 \mathrm{DM}$, metformin was associated with a lower cancer risk of liver (OR, $0.34 ; 95 \% \mathrm{CI}, 0.19$ to 0.60 ), colorectum (OR, $0.83 ; 95 \% \mathrm{CI}, 0.74$ to 0.92 ), pancreas (OR, 0.56 ; $95 \%$ CI, 0.36 to 0.86 ) and esophagus (OR, 0.90; 95\% CI, 0.83 to 0.98$).^{79}$ Other meta-analyses have also reported lower cancer risk of breast, prostate, endometrium and lung with metformin use. ${ }^{78}$

Indirect effects of metformin include the modulation of (1) the interaction between GC cells and their microenvironment and (2) gut microbiota. ${ }^{80}$ Co-culturing GC cells with metformin-pretreated gastric tumor-associated fibroblasts was observed to reduced GC cell proliferation. ${ }^{81}$ In addition, in-vivo and in-vitro experiments have demonstrated antibiotic properties of metformin in inhibiting H. pylori, in a dose-dependent manner. ${ }^{82}$ Metformin also induced solid tumor rejection in mice via an activation of CD8 + tumor-infiltrating lymphocytes (TILs). With uninhibited cancer growth, TILs progressively lose their ability to secrete interleukin-2, tumor necrosis factor $\alpha$, and interferon $\gamma$ and eventually undergo apoptosis in an immune exhaustion process. Metformin treatment prevented this TILs-apoptosis and induced TILs migration into tumors to reactivate anti-tumor immunity. ${ }^{83}$ It has recently been shown that metformin is able to modulate gut microbiota, ${ }^{84}$ Whether the gut microbiota changes induced by metformin will in turn influence GC risk necessitates further investigations.

\section{Chemopreventive effect of metformin on GC development in clinical studies}

Table 2 summarizes the results of five recent metaanalyses on the potential chemopreventive effect of metformin on GC. While protective effects with varying effect

Table 2. Summary of Meta-Analyses on the Potential Chemopreventive Effect of Metformin on Gastric Cancer

\begin{tabular}{|c|c|c|c|c|}
\hline Author (year) & Literature search & Study design & No. of included studies & Pooled risk ratio $(95 \% \mathrm{CI})$ \\
\hline \multirow[t]{3}{*}{ Wang et al. $(2021)^{85}$} & \multirow[t]{3}{*}{ Inception till August 9, 2020} & Cohort studies & 14 & $0.78(0.69-0.88)$ \\
\hline & & Presence of immortal time bias & 6 & 0.67 (0.59-0.77) \\
\hline & & Absence of immortal time bias & 8 & $0.95(0.85-1.05)$ \\
\hline \multirow[t]{3}{*}{ Shuai et al. $(2020)^{86}$} & \multirow[t]{3}{*}{ Inception till October 22, 2019} & Cohort studies & $11^{*}$ & $0.79(0.62-1.00)$ \\
\hline & & Asian population & 3 & $0.54(0.38-0.78)$ \\
\hline & & Western population & 5 & 0.99 (0.99-0.99) \\
\hline \multirow[t]{3}{*}{ Zhou et al. $(2017)^{87}$} & \multirow[t]{3}{*}{ Inception till November 2016} & Cohort studies & 7 & $0.76(0.64-0.91)$ \\
\hline & & China & 4 & $0.51(0.38-0.69)$ \\
\hline & & Outside of China & 3 & $0.90(0.80-1.02)$ \\
\hline Li et al. $(2017)^{88}$ & Inception till June 30, 2016 & Cohort studies & 5 & $0.87(0.73-1.04)$ \\
\hline \multirow[t]{2}{*}{ Franciosi et al. (2013) ${ }^{79}$} & \multirow[t]{2}{*}{ January 1966 till April 2012} & Cohort studies & 2 & $0.83(0.76-0.90)$ \\
\hline & & $\begin{array}{l}\text { Randomized controlled trials } \\
\text { (post-hoc analysis) }\end{array}$ & 2 & $0.48(0.11-2.02)$ \\
\hline
\end{tabular}

$\mathrm{Cl}$, confidence interval.

*There are 6 studies in West and 5 studies in Asia. However, for subgroup analysis, the authors only report the results for 3 Asian studies and 5 Western studies. 
estimate were shown for some studies, ${ }^{89,90}$ others failed to demonstrate such association. ${ }^{91-95}$ A meta-analysis of seven cohort studies in 2017 showed that metformin was associated with a $24 \%$ lower GC risk, ${ }^{87}$ but a recent meta-analysis of 14 cohort studies reported a similar magnitude of effect (21\% lower risk) albeit with borderline significance (95\% CI, 0.63 to $1.00 ; p=0.051)$. Subgroup analysis showed that the beneficial effect was limited to Asians (pooled RR, 0.54; $95 \%$ CI, 0.38 to 0.78 ) but not the Western population. Due to a lack of RCTs, the chemopreventive role of metformin in GC remains controversial based on data from observational studies. As an example, in two population-based retrospective cohort studies, the baseline characteristics differed between metformin users and non-users, including age, sex, socioeconomic status, concomitant use of other oral anti-diabetic medications and glycemic control. ${ }^{92,96}$ Hence, the seemingly beneficial effect of metformin on GC prevention may be due to the difference in these risk factors instead. Despite the use of multivariable analysis or propensity score analysis, residual confounding may still be present. ${ }^{97}$

Nonetheless, a dose- and duration-response relationship may help to strengthen the possibility of causality. In a territory-wide cohort study in Hong Kong, the aHRs of GC with a cumulative defined daily dose (cDDD) of $<975$ (median cDDD) and $\geq 975$ was 0.73 (95\% CI, 0.35 to 1.53 ) and 0.33 (95\% CI, 0.13 to 0.86 ), respectively, when compared with metformin non-users. ${ }^{96}$ This study also showed that the GC risk was lower with increasing duration of metformin use (aHR, $0.85 ; 95 \%$ CI, 0.74 to 0.96 for every 1 year increase in use); this effect size was similarly reported in a Korean nationwide cohort study (aHR, 0.88; 95\% CI, 0.81 to 0.96$).{ }^{92}$ Both studies reported the beneficial effect was observed only among those who used metformin for at least 3 years (aHR, $0.35 ; 95 \% \mathrm{CI}, 0.16$ to 0.80 ; aHR, 0.57 ; $95 \%$ CI, 0.37 to 0.87 , respectively). ${ }^{92,96}$

Importantly, other important risk factors of GC such as $H$. pylori infection, and DM severity have not been adequately addressed in previous studies, potentially undermining the effect of metformin on GC prevention. As H. pylori is the most important risk factor of GC, failure to stratify patients according to $H$. pylori status will affect the true effect estimate of metformin on GC development. Moreover, GC risk was shown to be higher among individuals with higher $\mathrm{HbAlc}$ levels ${ }^{29}$ and fasting plasma glucose. ${ }^{98} \mathrm{H}$. pylori infection and a higher HbAlc level $(\geq 6.0 \%)$ had a synergistic effect on GC risk. ${ }^{29}$ The protective effect of metformin on GC may therefore be due to a better glycemic control instead of the anti-cancer effects. This study, however, did not adjust for the effect of various medications and comorbidities, and therefore the independent role of $\mathrm{HbAlc}$ level remains to be investigated. In addition, the severity of DM affects the use of other DM drugs, which may confound the observed chemopreventive effect of metformin on GC. It has been reported that metformin significantly reduced GC risk in non-insulin users only, ${ }^{92}$ as insulin use may increase cancer risk via the insulin and IGF signaling systems.

To address the confounding factors of $H$. pylori infection, glycemic control and insulin use, we have previously conducted a territory-wide study of 7,266 DM patients with $H$. pylori-eradicated and followed up for a median of 7.1 years. ${ }^{96}$ The overall glycemic effect in addition to other covariates were considered in the multivariable analysis. As $\mathrm{HbAlc}$ varies with time, the time-weighted average $\mathrm{HbAlc}$ was used to represent the overall glycemic control during the observation period, which was derived as the average $\mathrm{HbAlc}$ weighted by the time interval between successive measurements. We found that metformin use was associated with a reduced GC risk (aHR, 0.49; 95\% CI, 0.24 to 0.98 ). This association was independent of glycemic control. Our findings support the plausible biological mechanisms that metformin prevents GC not through better glycemic control. However, the limited number of GC outcomes $(n=37)$ did not allow an in-depth study of whether this beneficial effect of metformin effect differs between the cardia and non-cardia GC.

Other concerns of the chemopreventive effect of metformin are time-related biases, including immortal time bias and time-window bias. ${ }^{99}$ Immortal time bias arises when there is an inappropriate exclusion of immortal time or an erroneous assignment of immortal time to the exposed group due to the definition of exposure. ${ }^{100}$ This immortal time biases the results towards an overestimation of the beneficial effects of a treatment. A recent metanalysis of 14 cohort studies by Wang et al..$^{85}$ showed that pooled RR from six cohort studies with immortal time bias was 0.67 (95\% CI, 0.59 to 0.77), while no beneficial effect of metformin (pooled RR, $0.95 ; 95 \%$ CI, 0.85 to 1.05 ) was shown from eight cohort studies without immortal time bias (Table 2). Meta-regression showed that presence of immortal time bias was associated with a reduction of $29 \%$ in the pooled RR. For cohort study design, this bias can be addressed by treating the exposure as a time-dependent covariate in the survival analysis modeling (in which the observation period is disintegrated into certain intervals and medication usage is defined in each interval) instead of time-fixed analysis. On the other hand, time-window bias arises in the context of case-control studies due to use of time-windows of different lengths between cases and controls to define time-dependent exposures. ${ }^{101}$ Nested case-control studies are less likely to suffer from immortal 
time bias and time-window bias as a result of incidencedensity sampling. However, the scientific value of positive studies that have not addressed immortal time bias should not be indiscriminately disregarded. This is evidenced by a similar conclusion on the beneficial effect of metformin between time-dependent analysis (by treating metformin as time-varying covariates) ${ }^{102}$ and time-fixed analysis in our territory-wide study of $H$. pylori-eradicated DM patients. ${ }^{96}$

While RCTs may be difficult to be conducted due to the long lag time and low incidence of GC development, future nested case control or cohort studies should address the flaws of current studies including confounding effect of $H$. pylori infection status, glycemic control and time-related biases in addition to other known risk factors of GC.

\section{CONCLUSIONS}

GC remains a common cancer with poor prognosis. Although $H$. pylori infection is the most important causative factor of GC, DM is another risk factor that has a synergistic effect with $H$. pylori infection on increasing GC risk. Metformin has been shown to potentially modify the GC risk, even after $H$. pylori eradication. The chemopreventive effect of metformin appears to be independent of glycemic control. Nevertheless, current studies are limited to observational studies and future prospective studies addressing various concerns and biases are needed to fully discern the potential role of metformin in preventing GC.

\section{CONFLICTS OF INTEREST}

No potential conflict of interest relevant to this article was reported.

\section{AUTHOR CONTRIBUTIONS}

Study conception: K.S.C., W.K.L. Acquisition of data: K.S.C. Drafting of manuscript: K.S.C., K.L.C. Revision of manuscript, and final approval of manuscript: W.K.L.

\section{ORCID}

Ka Shing Cheung https://orcid.org/0000-0002-4838-378X Kit Lam Chung https://orcid.org/0000-0003-1264-6602 Wai K. Leung https://orcid.org/0000-0002-5993-1059

\section{REFERENCES}

1. Bray F, Ferlay J, Soerjomataram I, Siegel RL, Torre LA, Jemal A. Global cancer statistics 2018: GLOBOCAN estimates of incidence and mortality worldwide for 36 cancers in 185 countries. CA Cancer J Clin 2018;68:394-424.

2. Fock KM. Review article: the epidemiology and prevention of gastric cancer. Aliment Pharmacol Ther 2014;40:250-260.

3. Cervantes A, Roda D, Tarazona N, Roselló S, Pérez-Fidalgo JA. Current questions for the treatment of advanced gastric cancer. Cancer Treat Rev 2013;39:60-67.

4. Van Cutsem E, Sagaert X, Topal B, Haustermans K, Prenen H. Gastric cancer. Lancet 2016;388:2654-2664.

5. Cavaleiro-Pinto M, Peleteiro B, Lunet N, Barros H. Helicobacter pylori infection and gastric cardia cancer: systematic review and meta-analysis. Cancer Causes Control 2011;22:375-387.

6. Infection with Helicobacter pylori. IARC Monogr Eval Carcinog Risks Hum 1994;61:177-240.

7. Hooi JKY, Lai WY, Ng WK, et al. Global prevalence of Helicobacter pylori infection: systematic review and metaanalysis. Gastroenterology 2017;153:420-429.

8. International Agency for Research on Cancer. Helicobacter pylori eradication as a strategy for preventing gastric cancer. IARC Working Group Reports. Volume 8. Geneva: WHO Press, 2014.

9. Correa P, Piazuelo MB, Camargo MC. The future of gastric cancer prevention. Gastric Cancer 2004;7:9-16.

10. Song H, Ekheden IG, Zheng Z, Ericsson J, Nyrén O, Ye W. Incidence of gastric cancer among patients with gastric precancerous lesions: observational cohort study in a low risk Western population. BMJ 2015;351:h3867.

11. Ford AC, Yuan Y, Moayyedi P. Helicobacter pylori eradication therapy to prevent gastric cancer: systematic review and meta-analysis. Gut 2020;69:2113-2121.

12. Wong BC, Lam SK, Wong WM, et al. Helicobacter pylori eradication to prevent gastric cancer in a high-risk region of China: a randomized controlled trial. JAMA 2004;291:187194.

13. Chen HN, Wang Z, Li X, Zhou ZG. Helicobacter pylori eradication cannot reduce the risk of gastric cancer in patients with intestinal metaplasia and dysplasia: evidence from a meta-analysis. Gastric Cancer 2016;19:166-175.

14. Pimanov SI, Makarenko EV, Voropaeva AV, Matveenko ME, Voropaev EV. Helicobacter pylori eradication improves gastric histology and decreases serum gastrin, pepsinogen I and pepsinogen II levels in patients with duodenal ulcer. J Gastroenterol Hepatol 2008;23:1666-1671.

15. Rokkas T, Pistiolas D, Sechopoulos P, Robotis I, Margantinis G. The long-term impact of Helicobacter pylori eradication on gastric histology: a systematic review and meta-analysis. 
Helicobacter 2007;12 Suppl 2:32-38.

16. Watari J, Das KK, Amenta PS, et al. Effect of eradication of Helicobacter pylori on the histology and cellular phenotype of gastric intestinal metaplasia. Clin Gastroenterol Hepatol 2008;6:409-417.

17. Hwang YJ, Kim N, Lee HS, et al. Reversibility of atrophic gastritis and intestinal metaplasia after Helicobacter pylori eradication: a prospective study for up to 10 years. Aliment Pharmacol Ther 2018;47:380-390.

18. Li WQ, Ma JL, Zhang L, et al. Effects of Helicobacter pylori treatment on gastric cancer incidence and mortality in subgroups. J Natl Cancer Inst 2014;106:dju116.

19. Cheung KS, Leung WK. Risk of gastric cancer development after eradication of Helicobacter pylori. World J Gastrointest Oncol 2018;10:115-123.

20. Yoon JM, Son KY, Eom CS, Durrance D, Park SM. Preexisting diabetes mellitus increases the risk of gastric cancer: a meta-analysis. World J Gastroenterol 2013;19:936-945.

21. Saeedi P, Petersohn I, Salpea P, et al. Global and regional diabetes prevalence estimates for 2019 and projections for 2030 and 2045: results from the International Diabetes Federation Diabetes Atlas, 9th edition. Diabetes Res Clin Pract 2019;157:107843.

22. Pollak M. Insulin and insulin-like growth factor signalling in neoplasia. Nat Rev Cancer 2008;8:915-928.

23. Tanigawa N, Amaya H, Matsumura M, Shimomatsuya T. Correlation between expression of vascular endothelial growth factor and tumor vascularity, and patient outcome in human gastric carcinoma. J Clin Oncol 1997;15:826-832.

24. Lorenzi M, Montisano DF, Toledo S, Barrieux A. High glucose induces DNA damage in cultured human endothelial cells. J Clin Invest 1986;77:322-325.

25. Dandona $\mathrm{P}$, Thusu K, Cook S, et al. Oxidative damage to DNA in diabetes mellitus. Lancet 1996;347:444-445.

26. Yang P, Zhou Y, Chen B, et al. Overweight, obesity and gastric cancer risk: results from a meta-analysis of cohort studies. Eur J Cancer 2009;45:2867-2873.

27. Wijnhoven BP, Siersema PD, Hop WC, van Dekken H, Tilanus HW. Adenocarcinomas of the distal oesophagus and gastric cardia are one clinical entity. Rotterdam Oesophageal Tumour Study Group. Br J Surg 1999;86:529-535.

28. Bianchini F, Kaaks R, Vainio H. Overweight, obesity, and cancer risk. Lancet Oncol 2002;3:565-574.

29. Ikeda F, Doi Y, Yonemoto K, et al. Hyperglycemia increases risk of gastric cancer posed by Helicobacter pylori infection: a population-based cohort study. Gastroenterology 2009;136:1234-1241.

30. Kim TJ, Lee H, Min YW, et al. Diabetic biomarkers and the risk of proximal or distal gastric cancer. J Gastroenterol Hepatol 2016;31:1705-1710.

31. Miao ZF, Xu H, Xu YY, et al. Diabetes mellitus and the risk of gastric cancer: a meta-analysis of cohort studies. Oncotarget 2017;8:44881-44892.

32. Chen YL, Cheng KC, Lai SW, et al. Diabetes and risk of subsequent gastric cancer: a population-based cohort study in Taiwan. Gastric Cancer 2013;16:389-396.

33. Cheung KS, Chan EW, Chen L, Seto WK, Wong ICK, Leung WK. Diabetes increases risk of gastric cancer after Helicobacter pylori eradication: a territory-wide study with propensity score analysis. Diabetes Care 2019;42:1769-1775.

34. Hamada H, Haruma K, Mihara M, et al. High incidence of reflux oesophagitis after eradication therapy for Helicobacter pylori: impacts of hiatal hernia and corpus gastritis. Aliment Pharmacol Ther 2000;14:729-735.

35. Upala S, Jaruvongvanich V, Riangwiwat T, Jaruvongvanich S, Sanguankeo A. Association between Helicobacter pylori infection and metabolic syndrome: a systematic review and meta-analysis. J Dig Dis 2016;17:433-440.

36. Upala S, Sanguankeo A, Saleem SA, Jaruvongvanich V. Effects of Helicobacter pylori eradication on insulin resistance and metabolic parameters: a systematic review and metaanalysis. Eur J Gastroenterol Hepatol 2017;29:153-159.

37. Song X, Cai C, Jin Q, Chen X, Yu C. The efficacy of Helicobacter pylori eradication in diabetics and its effect on glycemic control: a systematic review and meta-analysis. Helicobacter 2021;26:e12781.

38. Shimoyama S. Diabetes mellitus carries a risk of gastric cancer: a meta-analysis. World J Gastroenterol 2013;19:69026910.

39. Sona MF, Myung SK, Park K, Jargalsaikhan G. Type 1 diabetes mellitus and risk of cancer: a meta-analysis of observational studies. Jpn J Clin Oncol 2018;48:426-433.

40. Tian T, Zhang LQ, Ma XH, Zhou JN, Shen J. Diabetes mellitus and incidence and mortality of gastric cancer: a metaanalysis. Exp Clin Endocrinol Diabetes 2012;120:217-223.

41. Ge Z, Ben Q, Qian J, Wang Y, Li Y. Diabetes mellitus and risk of gastric cancer: a systematic review and meta-analysis of observational studies. Eur J Gastroenterol Hepatol 2011;23:1127-1135.

42. Kuipers EJ, Lundell L, Klinkenberg-Knol EC, et al. Atrophic gastritis and Helicobacter pylori infection in patients with reflux esophagitis treated with omeprazole or fundoplication. N Engl J Med 1996;334:1018-1022.

43. Lundell L, Vieth M, Gibson F, Nagy P, Kahrilas PJ. Systematic review: the effects of long-term proton pump inhibitor use on serum gastrin levels and gastric histology. Aliment Pharmacol Ther 2015;42:649-663.

44. Cheung KS, Leung WK. Long-term use of proton-pump inhibitors and risk of gastric cancer: a review of the current evidence. Therap Adv Gastroenterol 2019;12:175628 4819834511.

45. Jiang K, Jiang X, Wen Y, Liao L, Liu FB. Relationship be- 
tween long-term use of proton pump inhibitors and risk of gastric cancer: a systematic analysis. J Gastroenterol Hepatol 2019;34:1898-1905.

46. Cheung KS, Chan EW, Wong AYS, Chen L, Wong ICK, Leung WK. Long-term proton pump inhibitors and risk of gastric cancer development after treatment for Helicobacter pylori: a population-based study. Gut 2018;67:28-35.

47. Lee JK, Merchant SA, Schneider JL, et al. Proton pump inhibitor use and risk of gastric, colorectal, liver, and pancreatic cancers in a community-based population. Am J Gastroenterol 2020;115:706-715.

48. Moayyedi P, Eikelboom JW, Bosch J, et al. Safety of proton pump inhibitors based on a large, multi-year, randomized trial of patients receiving rivaroxaban or aspirin. Gastroenterology 2019;157:682-691.

49. Bosetti C, Santucci C, Gallus S, Martinetti M, La Vecchia C. Aspirin and the risk of colorectal and other digestive tract cancers: an updated meta-analysis through 2019. Ann Oncol 2020;31:558-568.

50. Cheung KS, Leung WK. Modification of gastric cancer risk associated with proton pump inhibitors by aspirin after Helicobacter pylori eradication. Oncotarget 2018;9:36891-36893.

51. Keyomarsi K, Sandoval L, Band V, Pardee AB. Synchronization of tumor and normal cells from G1 to multiple cell cycles by lovastatin. Cancer Res 1991;51:3602-3609.

52. Dimitroulakos J, Marhin WH, Tokunaga J, et al. Microarray and biochemical analysis of lovastatin-induced apoptosis of squamous cell carcinomas. Neoplasia 2002;4:337-346.

53. Park HJ, Kong D, Iruela-Arispe L, Begley U, Tang D, Galper JB. 3-hydroxy-3-methylglutaryl coenzyme A reductase inhibitors interfere with angiogenesis by inhibiting the geranylgeranylation of RhoA. Circ Res 2002;91:143-150.

54. Kusama T, Mukai M, Iwasaki T, et al. 3-hydroxy-3-methylglutaryl-coenzyme a reductase inhibitors reduce human pancreatic cancer cell invasion and metastasis. Gastroenterology 2002;122:308-317.

55. Shaheen NJ, Straus WL, Sandler RS. Chemoprevention of gastrointestinal malignancies with nonsteroidal antiinflammatory drugs. Cancer 2002;94:950-963.

56. Cuzick J, Otto F, Baron JA, et al. Aspirin and non-steroidal anti- inflammatory drugs for cancer prevention: an international consensus statement. Lancet Oncol 2009;10:501-507.

57. Yamamoto Y, Yin MJ, Lin KM, Gaynor RB. Sulindac inhibits activation of the NF-kappaB pathway. J Biol Chem 1999;274:27307-27314.

58. Patrignani P, Patrono C. Aspirin and cancer. J Am Coll Cardiol 2016;68:967-976.

59. Singh PP, Singh S. Statins are associated with reduced risk of gastric cancer: a systematic review and meta-analysis. Ann Oncol 2013;24:1721-1730.

60. Cheung KS, Chan EW, Wong AYS, et al. Aspirin and risk of gastric cancer after Helicobacter pylori eradication: a territory- wide study. J Natl Cancer Inst 2018;110:743-749.

61. Cheung KS, Chan EW, Wong AYS, et al. Statins were associated with a reduced gastric cancer risk in patients with eradicated Helicobacter pylori infection: a territory-wide propensity score matched study. Cancer Epidemiol Biomarkers Prev 2020;29:493-499.

62. Sung JJ, Leung WK, Go MY, et al. Cyclooxygenase-2 expression in Helicobacter pylori-associated premalignant and malignant gastric lesions. Am J Pathol 2000;157:729-735.

63. Leung WK, Ng EK, Chan FK, et al. Effects of long-term rofecoxib on gastric intestinal metaplasia: results of a randomized controlled trial. Clin Cancer Res 2006;12:4766-4772.

64. Wong BC, Zhang L, Ma JL, et al. Effects of selective COX-2 inhibitor and Helicobacter pylori eradication on precancerous gastric lesions. Gut 2012;61:812-818.

65. Li B, Cheung KS, Wong IY, Leung WK, Law S. Nonaspirin nonsteroidal anti-inflammatory drugs and gastric cancer risk after Helicobacter pylori eradication: a territory-wide study. Cancer 2021;127:1805-1815.

66. Cerda-Opazo P, Valenzuela-Valderrama M, Wichmann I, et al. Inverse expression of survivin and reprimo correlates with poor patient prognosis in gastric cancer. Oncotarget 2018;9:12853-12867.

67. Yusufu A, Tuerdi R, Redati D, Rehemutula A, Zhao ZL, Wang HJ. Expression and clinical correlation of Survivin and PTEN in gastric cancer patients. Oncol Lett 2020;20:297.

68. Jalving M, Gietema JA, Lefrandt JD, et al. Metformin: taking away the candy for cancer? Eur J Cancer 2010;46:2369-2380.

69. Han G, Gong H, Wang Y, Guo S, Liu K. AMPK/mTORmediated inhibition of survivin partly contributes to metformin-induced apoptosis in human gastric cancer cell. Cancer Biol Ther 2015;16:77-87.

70. Kato K, Gong J, Iwama $\mathrm{H}$, et al. The antidiabetic drug metformin inhibits gastric cancer cell proliferation in vitro and in vivo. Mol Cancer Ther 2012;11:549-560.

71. Chia NY, Deng N, Das K, et al. Regulatory crosstalk between lineage- survival oncogenes KLF5, GATA4 and GATA6 cooperatively promotes gastric cancer development. Gut 2015;64:707-719.

72. Chiurillo MA. Role of the Wnt/ $\beta$-catenin pathway in gastric cancer: an in-depth literature review. World J Exp Med 2015;5:84-102.

73. Valaee S, Yaghoobi MM, Shamsara M. Metformin inhibits gastric cancer cells metastatic traits through suppression of epithelial-mesenchymal transition in a glucose-independent manner. PLoS One 2017;12:e0174486.

74. Jun KH, Lee JE, Kim SH, et al. Clinicopathological significance of N-cadherin and VEGF in advanced gastric cancer brain metastasis and the effects of metformin in preclinical models. Oncol Rep 2015;34:2047-2053. 
75. Huang D, He X, Zou J, et al. Negative regulation of Bmi-1 by AMPK and implication in cancer progression. Oncotarget 2016;7:6188-6200.

76. Song Z, Wei B, Lu C, Huang X, Li P, Chen L. Metformin suppresses the expression of Sonic hedgehog in gastric cancer cells. Mol Med Rep 2017;15:1909-1915.

77. Courtois S, Durán RV, Giraud J, et al. Metformin targets gastric cancer stem cells. Eur J Cancer 2017;84:193-201.

78. Heckman-Stoddard BM, DeCensi A, Sahasrabuddhe VV, Ford LG. Repurposing metformin for the prevention of cancer and cancer recurrence. Diabetologia 2017;60:1639-1647.

79. Franciosi M, Lucisano G, Lapice E, Strippoli GF, Pellegrini F, Nicolucci A. Metformin therapy and risk of cancer in patients with type 2 diabetes: systematic review. PLoS One 2013;8:e71583.

80. Courtois S, Lehours P, Bessède E. The therapeutic potential of metformin in gastric cancer. Gastric Cancer 2019;22:653662.

81. Chen G, Yu C, Tang Z, et al. Metformin suppresses gastric cancer progression through calmodulin-like protein 3 secreted from tumor-associated fibroblasts. Oncol Rep 2019;41:405-414

82. Courtois S, Bénéjat L, Izotte J, et al. Metformin can inhibit Helicobacter pylori growth. Future Microbiol 2018;13:15751583.

83. Eikawa S, Nishida M, Mizukami S, Yamazaki C, Nakayama E, Udono H. Immune-mediated antitumor effect by type 2 diabetes drug, metformin. Proc Natl Acad Sci U S A 2015;112:1809-1814

84. Wu H, Esteve E, Tremaroli V, et al. Metformin alters the gut microbiome of individuals with treatment-naive type 2 diabetes, contributing to the therapeutic effects of the drug. Nat Med 2017;23:850-858.

85. Wang YB, Tan LM, Luo L, et al. Immortal time bias exaggerates the effect of metformin on the risk of gastric cancer: a meta-analysis. Pharmacol Res 2021;165:105425.

86. Shuai Y, Li C, Zhou X. The effect of metformin on gastric cancer in patients with type 2 diabetes: a systematic review and meta-analysis. Clin Transl Oncol 2020;22:1580-1590.

87. Zhou XL, Xue WH, Ding XF, et al. Association between metformin and the risk of gastric cancer in patients with type 2 diabetes mellitus: a meta-analysis of cohort studies. Oncotarget 2017;8:55622-55631.

88. Li P, Zhang C, Gao P, et al. Metformin use and its effect on gastric cancer in patients with type 2 diabetes: a systematic review of observational studies. Oncol Lett 2018;15:11911199.

89. Lee MS, Hsu CC, Wahlqvist ML, Tsai HN, Chang YH, Huang YC. Type 2 diabetes increases and metformin reduces total, colorectal, liver and pancreatic cancer incidences in Taiwanese: a representative population prospective cohort study of 800,000 individuals. BMC Cancer 2011;11:20.

90. Home PD, Kahn SE, Jones NP, et al. Experience of malignancies with oral glucose-lowering drugs in the randomised controlled ADOPT (A Diabetes Outcome Progression Trial) and RECORD (Rosiglitazone Evaluated for Cardiovascular Outcomes and Regulation of Glycaemia in Diabetes) clinical trials. Diabetologia 2010;53:1838-1845.

91. Ruiter R, Visser LE, van Herk-Sukel MP, et al. Lower risk of cancer in patients on metformin in comparison with those on sulfonylurea derivatives: results from a large populationbased follow-up study. Diabetes Care 2012;35:119-124.

92. Kim YI, Kim SY, Cho SJ, et al. Long-term metformin use reduces gastric cancer risk in type 2 diabetics without insulin treatment: a nationwide cohort study. Aliment Pharmacol Ther 2014;39:854-863.

93. Hsieh MC, Lee TC, Cheng SM, Tu ST, Yen MH, Tseng $\mathrm{CH}$. The influence of type 2 diabetes and glucose-lowering therapies on cancer risk in the Taiwanese. Exp Diabetes Res 2012;2012:413782.

94. Tseng CH. Metformin reduces gastric cancer risk in patients with type 2 diabetes mellitus. Aging (Albany NY) 2016;8:1636-1649.

95. Valent F. Diabetes mellitus and cancer of the digestive organs: an Italian population-based cohort study. J Diabetes Complications 2015;29:1056-1061.

96. Cheung KS, Chan EW, Wong AYS, et al. Metformin use and gastric cancer risk in diabetic patients after Helicobacter pylori eradication. J Natl Cancer Inst 2019;111:484-489.

97. Cheung KS, Leung WK, Seto WK. Application of Big Data analysis in gastrointestinal research. World J Gastroenterol 2019;25:2990-3008.

98. Yamagata H, Kiyohara Y, Nakamura S, et al. Impact of fasting plasma glucose levels on gastric cancer incidence in a general Japanese population: the Hisayama study. Diabetes Care 2005;28:789-794.

99. Suissa S, Azoulay L. Metformin and the risk of cancer: time-related biases in observational studies. Diabetes Care 2012;35:2665-2673.

100. Targownik LE, Suissa S. Understanding and avoiding immortal-time bias in gastrointestinal observational research. Am J Gastroenterol 2015;110:1647-1650.

101. Suissa S, Dell'aniello S, Vahey S, Renoux C. Time-window bias in case-control studies: statins and lung cancer. Epidemiology 2011;22:228-231.

102. Cheung KS, Leung WK. Response to Khosrow-Khavar, Kurteva, and Douros. J Natl Cancer Inst 2019;111:1109. 